\title{
Upcoming Webinars
}

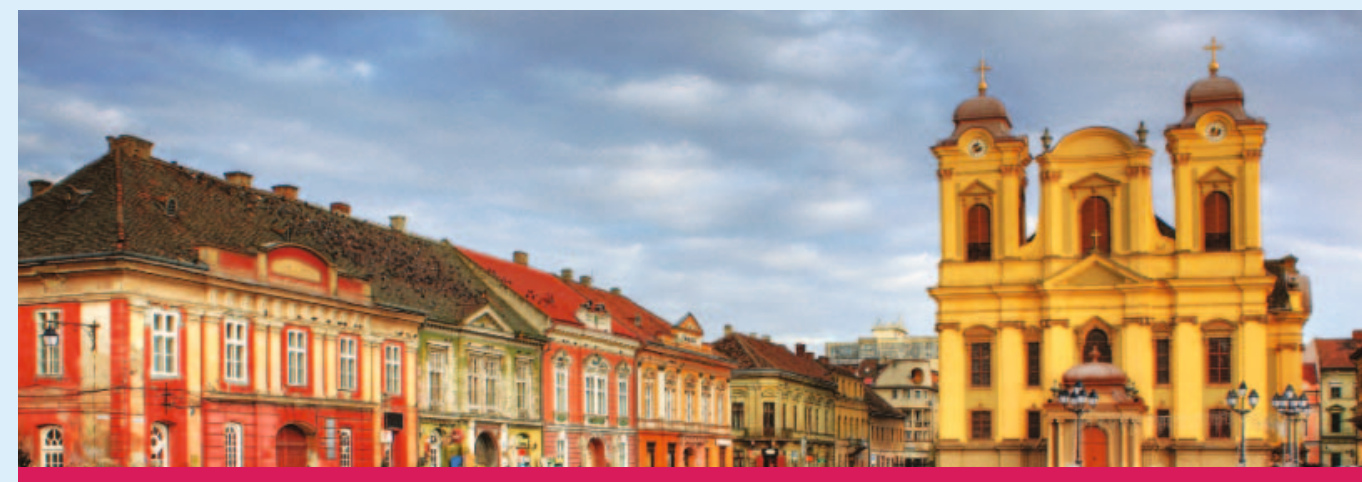

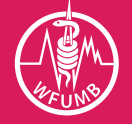

WFUMB 2022

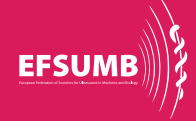

EUROSON 2022

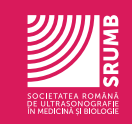

SRUMB 2022

The $18^{\text {th }}$ World Federation for Ultrasound in Medicine and Biology Congress WFUMB 2022

The $33^{\text {rd }}$ Congress of European Federation of Societies for Ultrasound in Medicine and Biology EUROSON 2022

The $24^{\text {th }}$ National Conference of The Romanian Society of Ultrasound in Medicine and Biology SRUMB 2022

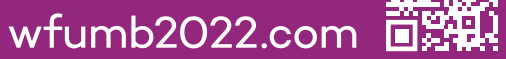

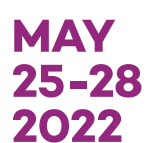

2022

Timișoara,

Convention

Center

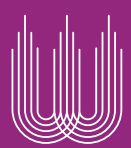

WFUMB CONGRESS 2022 TIMIȘOARA

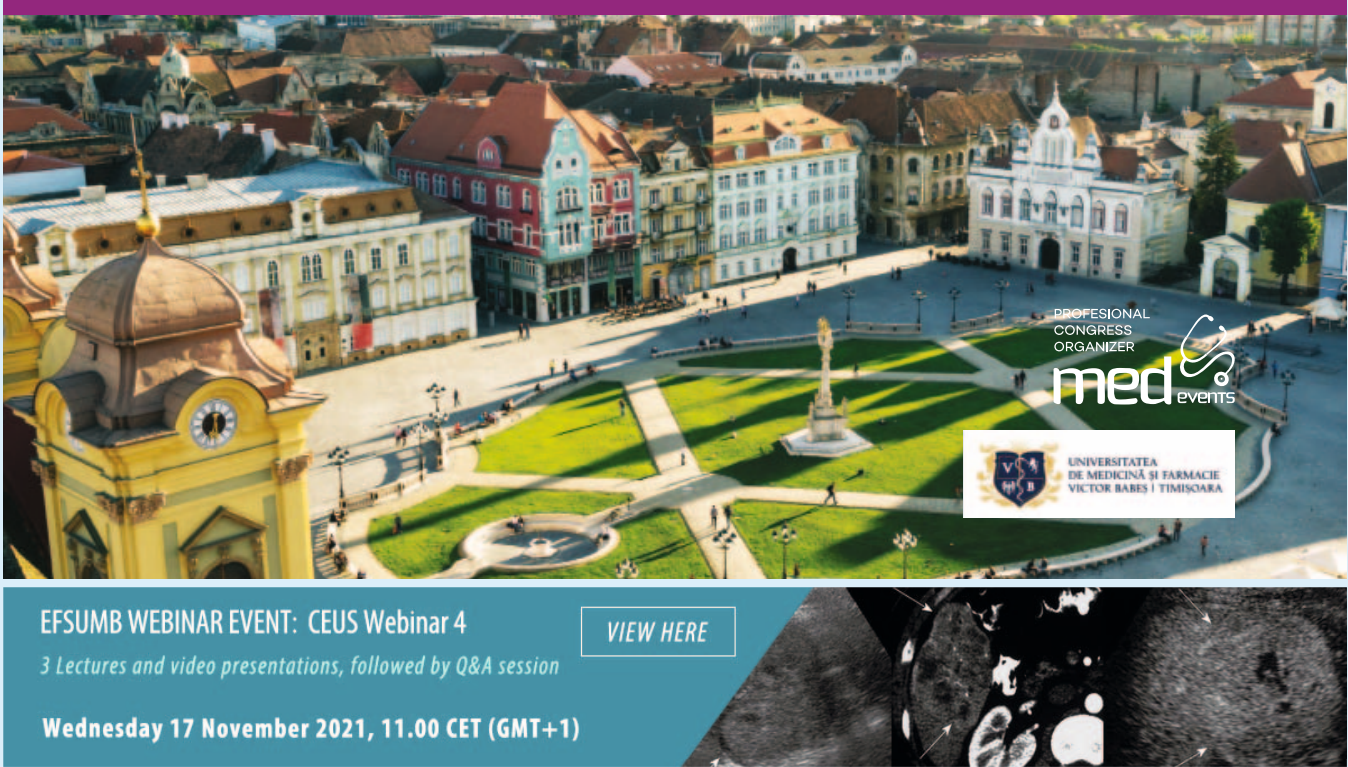

